\title{
La creación poética como crítica
}

\author{
Poetic Creation as Criticism
}

\author{
SERGIO MANSILLA TORRES ${ }^{a}$ \\ ${ }^{a}$ Universidad Austral de Chile. Facultad de Filosofía y Humanidades. \\ Instituto de Lingüística y Literatura, Chile. \\ Correo electrónico: sergio.mansilla@uach.cl
}

En este artículo se propone una mirada sobre la poesía como una práctica lingüístico-discursiva de indocilidad cuyo efecto crítico acontece en el lenguaje y, por consecuencia, en las estructuras de sentido y de sentir que el ser humano construye sobre su vivir. Plantear la creación poética como crítica es aquí más un pretexto que una tesis; pretexto a partir del cual se elabora una aproximación a la poesía enfocada en insistir en su valor emancipatorio a la hora de tratar con la subjetividad humana.

Palabras claves: Poesía, crítica, subjetividad, creación poética, razón poética.

This article proposes a look at poetry as a linguistic-discursive practice of indocility whose critical effect occurs in language and, consequently, in the structures of meaning and the structure of feeling that the human being builds on his living. Presenting poetic creation as criticism is here more a pretext than a thesis; a pretext from which an approach to poetry is developed, focused on insisting on its emancipatory value at moment when poetry deals with human subjectivity.

Key words: Poetry, criticism, subjectivity, poetic creation, poetic reason. 


\section{A MOdo DE INTRODUCCIÓN: DISCERNIMIENTO, LUCIDEZ, EXTRAŃEZA}

Si el vocablo "crítica”, derivado del griego "krinein”, alude a "discernir", "analizar", "separar", el vocablo "creación", del latín "creatio", alude a inventar, establecer o instituir algo, otorgarle existencia a una cierta entidad que antes de la acción creadora respectiva no existía. ${ }^{1}$ Así visto, el acto de discernir, analizar o separar implica previamente la existencia de una determinada entidad, situación o proceso susceptible de ser objeto de crítica. La crítica literaria, por ejemplo, se distingue de la creación literaria en que la primera opera sobre obras ya existentes, previamente producidas o creadas por uno o varios autores a través de un trabajo en y con el lenguaje; en tanto la segunda se suele normalmente concebir como una práctica de escritura que da forma y existencia a una obra nueva, que aparece - y para decirlo de un modo ilustrativamente incorrecto- " como de la nada" por obra y gracia de la imaginación creadora ajustada, claro está, a las exigencias expresivas y estéticas propias del género textual / literario que corresponda. La crítica — de la literatura en este caso- aparece como una actividad secundaria, derivativa, metatextual, mientras que la creación poética —objeto principal de estas disquisiciones - sería primaria, textual, cuyo ámbito de trabajo se inscribiría en el de la "traducción" a texto de percepciones, visiones, ensońaciones, experiencias de aquella realidad que está más allá o más acá, pero siempre fuera, de los textos que la refieren y significan.

Ciertamente la crítica no es reducible a crítica textual. En su sentido más amplio y seminal, la crítica es en ocasiones un ejercicio de develamiento; en otras lo es de desmitificación. A menudo es igualmente un ejercicio de historización de los modos de hacer sentido del vivir humano en determinados contextos, situaciones, territorios, etc. No sería, pues, descaminado ver la crítica como un vasto y nunca clausurado ejercicio humano de entender y comprender cómo funciona el mundo — nuestra realidad en particular - y cómo situarse en y ante él de manera tal que nos sintamos lo suficientemente libres y responsables como para asumir posiciones conscientemente decantadas y actuar en consecuencia. La sonrisa de la Ilustración se hace notar, sin duda, en este planteamiento en cuanto que nos aferramos a la confianza que solemos tener en la capacidad de la mente racional para discernir, separar y analizar con el tino suficiente y luego entonces proceder según el mejor entendimiento

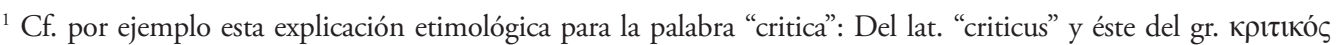
"kritikós" "capaz de discernir", proveniente del verbo kpíveıv "krínein" "separar, decidir, juzgar", de raíz indoeuropea *krei- "cribar, discriminar, distinguir" y emparentado con el lat. "cerno" "separar" (cf. "dis-cernir"), "cribrum" "criba" y "crimen" "juicio, acusación" (compárese con el gr. кpífa "kríma" "juicio"), con el germ. *hridra, de donde viene en ang. saj. "hriddel", en ingl. "riddle" "criba", con el irl. ant. "criathar" "criba". En: https://etimologia.wordpress. com/2007/09/04/critica/ [7-07-2020]. En tanto el Diccionario de la Lengua Española de la RAE establece para la

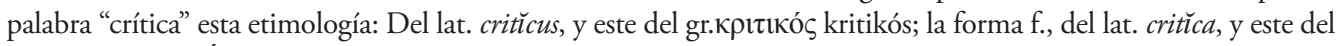
gr. крıєıкń kritikế. De las 13 acepciones que distingue este Diccionario solo la acepción Nro. 9 se acerca a la línea de discusión que desarrollo en estas notas: "Juicio expresado, generalmente de manera pública, sobre un espectáculo, una obra artística, etc." Ver: https://dle.rae.es/crítico [7-07-2020]. La etimología latina de la palabra "creación" la tomo del Diccionario de la RAE antes citado. Por su parte, la poeta y escritora colombiana Piedad Bonett Vélez en "Apuntes sobre el proceso de la creación poética", de 2009, elabora una sugerente aproximación al concepto y a la práctica de la "creación poética" que va en la línea de la discusión que aquí propongo.
} 
posible acerca de las cosas del mundo y sus laberintos. Hablo de la capacidad de elaborar juicios despojados de atrabiliarios actos de fe, libres de prejuicios refractarios a escrutinios razonados, contrarios a toda clase de asertos cuyos fundamentos empíricos o lógicos son (o serían) cuando menos difusos o, en el peor de los casos, abiertamente inexistentes.

Como fuere, la crítica en tanto escrutinio de los modos de ser y existir de la realidad, al igual que la creación poética, se nos presenta como una práctica de producir significaciones de tales modos, lo que implica, desde luego, interpretación y análisis cuando menos; algo que, en el caso específico de la crítica, toma la forma de una exposición razonada de la situación con un lenguaje que, si no es filosófico, suele estar bastante cerca de él. Esto por encima de si a un determinado ejercicio crítico se le pueda calificar de crítica política, cultural, literaria, filosófica, teológica, etc.

Después de todo —escribe Michel Foucault— la crítica existe en relación con algo distinto de ella: es instrumento, es medio para un porvenir o una verdad que ella no conocerá o no será; es una mirada sobre un dominio donde sin duda le gusta hacer de policía y donde no es capaz de hacer ley. Todo esto hace de ella una función que ocupa una posición subordinada respecto de lo que constituyen positivamente la filosofía, la ciencia, la política, la moral, el derecho, la literatura, etc. (2018: 48-49).

Subordinado o no, la función de la crítica la veo como ejercicio de instalar extrańezas ahí donde la costumbre y la rutina tornan invisible lo que siempre debiera verse en su opacidad reveladora de una materia que laboriosamente trabaja a favor de un existir concreto, existir que no cesa de reclamar reconocimiento acerca de su complejidad, de sus fracturas, de sus tensiones. La función de la crítica es educativa, si se quiere; un ejercicio de solidaridad humana contra la ignorancia, la falta de lucidez o la falta de moral inclusive. A este respecto, Auden, en lo que específicamente concierne a la crítica literaria, la ve como una prestadora, al decir del autor, de "uno o más de los siguientes servicios" (2013: 33):

1. Darme a conocer autores que hasta ese momento ignoraba.

2. Convencerme de que he menospreciado a cierto autor o determinada obra por no haberla leído con suficiente cuidado.

3. Mostrarme relaciones entre obras de distintas épocas y culturas que jamás habría descubierto por mí mismo porque no sé lo suficiente y jamás lo sabré.

4. Ofrecerme una «lectura» de determinada obra que mejore mi comprensión de la misma.

5. Arrojar luz sobre el proceso del «hacer» artístico.

6. Arrojar luz sobre el arte de vivir, sobre la ciencia, la economía, la ética, la religión, etcétera.

De estos servicios, los tres primeros requieren erudición [...] En cuanto a los tres últimos servicios, no requieren un conocimiento superior, sino una mayor lucidez (2013: 33). 
Puede quizás sorprender que, en materia de producción de significaciones acerca del mundo (los textos son parte del mundo, ciertamente), esté yo "igualando" la crítica con la creación poética. ${ }^{2}$ No hay que pensar demasiado — solo es cosa de observar- para percatarse de las diferencias existentes entre la actividad crítica y la actividad creativa en el campo poético. El peso específico de la imaginación y la fantasía literaria domina en la creación poética, cuyos textos resultantes quedan de entrada dispensados de la obligación de exponer, con discernimiento analítico y razonado, un cierto conjunto de juicios y conclusiones organizadas según un determinado orden de coherencia y consistencia argumentativa. Entonces ¿por qué pensar que la creación poética podría verse como crítica? Y de haber crítica ¿qué clase de crítica sería la que comporta la creación poética?

\section{LA POESÍA ES UN ASUNTO DE LENGUAJE}

Lo primero que habría que dejar establecido es que la creación literaria no sucede ex nihilo, si bien cierta tradición de resonancias románticas ha elevado al poeta a la condición de "creador" en un sentido que se asemeja — demasiado, me parece — a la imagen de un dios. La tesis de Huidobro - menciono a este autor solo a modo de ejemplo ilustrativo de los intríngulis que suscita la concepción del poeta como "creador" - de que el poeta es un "pequeño dios" nos lleva a la escena en la que el poeta se define por haber creado (y por tener que crear) mundos nuevos poco o nada miméticos en relación con aquello que llamamos, con razón o sin ella, "mundo real". ${ }^{3}$ Mas, si atendemos al adjetivo "pequeño", y por añadidura antepuesto al sustantivo, se hace patente que un poeta como Vicente Huidobro, que hizo de la noción de "creación" el pilar esencial de su mundo literario, sabía perfectamente que la creación poética no es sino solo figuradamente semejante a la creación en sentido absoluto, tal como se la dibuja en la concepción judeo-cristiana a la hora de imaginar el origen primero de todo lo que existe. Que el dios-poeta sea "pequeño", habla, sin duda, de que Huidobro siempre estuvo muy consciente de que los actos creativos del poeta siempre son, de un modo u otro, menores, que están muy por debajo de aquellos actos de la naturaleza, entidad que sí es capaz de crear vida genuina, de sostenerla, de transformarla, de crear por sí misma un medio ambiente sustentable. El resultado de la actividad creadora en poesía es, pues, materia de segundo orden respecto de las experiencias de mundo (real) que son, en definitiva, las fundantes primordiales de los lenguajes de la poesía.

\footnotetext{
${ }^{2}$ A lo largo de la exposición uso la expresión "creación poética" como un sinónimo laxo de "poesía", si bien con el vocablo "creación" enfatizo la actividad, el trabajo en rigor, de producir poesía con el lenguaje cuyos resultados concretos son los poemas. Con el vocablo "poesía" aludo aquí unas veces a la actividad misma de producirla, es decir, a la creación poética, y otras al conjunto de textos poéticos que, desde mi punto de vista, no cesan de ser de ser igualmente productividad poética en el ejercicio colectivo de leer y/o escribir poesía.

${ }^{3}$ Cf. su famosa "Arte poética" de 1916, incluida en su libro Espejo de agua, publicado en originalmente en Buenos Aires por Orión. En esta oportunidad tengo a la vista una edición de 2011.
} 
Significar la realidad en forma de poesía es un acontecimiento en el que confluyen varias circunstancias que se manifiestan en el terreno del autor: experiencias perceptivas de la inmediatez material del mundo; lecturas múltiples entre las cuales las lecturas de poesía otras, de cualquier época, canónicas o no, actúan como venero de la imaginación poética, de los estilos, de los tonos, de los modos de elaborar recuadros de realidad de valor poético; también confluyen ideas y actitudes sobre el mundo de la vida, sobre la función de la poesía, sobre los dilemas del bien y del mal; esto último vale si se considera que el poema, como acota Terry Eagleton, es, entre otras cosas, una "declaración moral" (2010:35). Como fuere, no perdamos de vista el hecho de que la poesía no se limita a ser la simple traducción a lenguaje literario o figurado de un cierto conjunto de ideas o convicciones alojadas en la mente del autor con anterioridad al acto de escritura. La poesía es, por encima de todo, un asunto de lenguaje, no de ideas, como decía Mallarmé, por más que ellas tengan igualmente un rol no despreciable a la hora de componer un poema. ${ }^{4}$

Que sea un asunto de lenguaje no debe llevarnos a pensar que la poesía es un asunto de comunicación de determinados mensajes a través del lenguaje fácilmente discernibles, como si este fuera solo un medio o un instrumento de inequívoca comunicación. Que sea un asunto de lenguaje entendámoslo, en principio, como un diálogo polifónico con el mundo (un sector de él en rigor), lo que, de partida, implica reconocer que en el mundo —eso que está más allá de los sujetos y que al mismo tiempo es aquello donde están y son los sujetos que viven - hay una dimensión lingüística que lo constituye, que (nos) habla, que reclama un lugar vital en el devenir de los discursos (y decursos, habría que agregar) humanos. Una manera de decir que el lenguaje, precisamente por ser tal, deviene lenguaje de las cosas no humanas, las cuales, entonces, y en la medida en que significan algo, ingresan a la escena de las subjetividades que expresan y se expresan. Después de todo, poetizar el mundo es hacer que este hable, personificarlo de alguna manera, otorgarle voz y oír y hacer oír sus susurros o sus gritos desaforados, según sea el caso. La poesía, la literatura en general, no deja, pues, de ser un acontecimiento que pone en evidencia que el lenguaje pertenece a todo y a todos, y que los poetas, cada quien a su modo desde luego, son (o sienten que lo son, que para el caso viene a ser lo mismo) amanuenses de ese lenguaje "total" que reverbera en todo lo que existe en un momento dado y en circunstancias muy concretas; lenguaje "total" que reclama su lugar en la conciencia y sensibilidad humana. La creación poética será entonces el trabajo de construirle a ese lenguaje informe, a ese magma poético deslocalizado, un lugar en la escena de las hablas humanas al uso; un lugar poderosamente significativo y singular a la hora de conformar y sostener la subjetividad.

Si hay crítica en la creación poética, esta será en, desde y con el lenguaje, siempre que no perdamos de vista el hecho de que, en esta escena, "lenguaje" es una palabra que alude a una vastedad polifónica de voces humanas y no humanas que recursivamente se

\footnotetext{
${ }^{4}$ Según lo que consigna Roberto Calasso, en su libro La Folie Baudelaire (2011), la afirmación extendida de Mallarmé es: "Las palabras pueden y deben bastarse a sí mismas. Tienen su potencial personal, su fuerza, su individualidad, su existencia propia. Tienen suficiente fuerza para resistir la agresión de las ideas". Cito del artículo de Roberto Appratto "Mallarmé y una frase capital sobre la literatura" (web).
} 
sostienen y que, a la vez, se transforman en el tiempo. La poesía será, entonces, el ejercicio de decodificar el zumbido del mundo y codificarlo nuevamente, por ejemplo, en un poema, de modo que este "zumbido del mundo" quede a disposición de los humanos en la forma de un artefacto poético hecho de lenguaje y sujeto a determinadas convenciones estéticas. "Escribir un poema — nos dice el poeta Gonzalo Millán— es una traducción en sí misma, que consiste en cifrar con palabras una experiencia no verbal" (2012: 63). Una "experiencia no verbal" que, a mi entender, nunca deja de ser igualmente verbal, si bien no organizada en la forma de un discurso lingüístico reconocible como un texto en el sentido convencional del término. Porque, en última instancia, y siguiendo ahora a Wittgenstein, los límites de nuestro mundo son los límites de nuestro lenguaje y viceversa. ${ }^{5}$ La poesía, por regla general, trabaja en las zonas límites del cifrado lingüístico del mundo, hecho de donde emana su potencia expresiva y de significación tanto como su derrota ante las ilimitadas exigencias de verbalización que nos impone la realidad. La creación poética es un duelo feroz entre las palabras y el silencio, mas también es un contubernio cómplice entre ambos órdenes de realidad. Dar cuenta de este doble y recursivo movimiento de enemistad y complicidad entre el silencio y la palabra en la forma de textos que describen o relatan episodios del existir cuya significación acontece en las zonas fronterizas del lenguaje, es tarea del poeta. Esto va en línea con la idea de que el poema es la historia de un yo, de un sujeto, que se hace en y con las palabras que conforman el poema; yo que se suele llamar "hablante lírico" pero que, bien mirado, es la figura humana hecha de y en ese lenguaje con el que las cosas del mundo "hablan" creando así un continuum entre lo humano y lo no humano, de modo que se cancela, imaginativamente al menos, esta separación.

"Desde mi primera obra, Tolstoi o Dostoievsky [la obra mencionada data de 1960], no he parado de decir que el creador está a años luz del que comenta o interpreta. Estoy convencido" (2016: 167). Así reza el taxativo juicio de uno de los más grandes críticos y pensadores de la literatura y del lenguaje del siglo XX: George Steiner. ¿Por qué un crítico, de la envergadura de Steiner, diría esto? Más allá de que semejante aserto responda a su personal apreciación sobre su propia empresa intelectual (de hecho, la compara con el trabajo del personaje el cartero que en la película Il Postino lleva y trae la correspondencia de Neruda), ${ }^{6}$ hay en él la invitación a un reto en el que me gustaría detenerme un momento. Si vemos al creador de poesía como una persona que, valiéndose de un idioma concreto, de la gramática de este, de su léxico, etc. emprende la tarea de extraterritorializar el lenguaje en el sentido

\footnotetext{
${ }^{5}$ En su Tractatus Lógico-Philosophicus Wittgenstein formula esta conocida afirmación: "Los límites de mi lenguaje significan los límites de mi mundo", que corresponde a la proposición 5.6 del Tractatus. Remito al lector al muy buen informado análisis de la afirmación de Wittgenstein que desarrolla David Coble Sarro en su trabajo "Límite de mi lenguaje como límite de mi mundo", de 2015.

6 "Así pues, ¿̨cuál es mi misión? Es la de ser un cartero, como en esa película estupenda, Il Postino. Es una película sobre Neruda y sobre ese hombre insignificante que lleva las cartas a Neruda y que empieza a darse cuenta de lo que quiere decir ser Neruda. A lo largo de mi vida he tratado de ser un buen cartero, de recoger las cartas y entregarlas en los buzones correctos" (Steiner 2016: 168-169).
} 
de desterrarlo de sus lugares comunes, de su convencional funcionalidad comunicativa, entonces estamos ante alguien que obliga al lenguaje (y se obliga a sí mismo al obligar el lenguaje) a lidiar con su propia capacidad de referir un cierto mundo. Al decir "mundo" aludo aquí a ese ámbito de realidad que constantemente cruza, en un sentido y en otro, los umbrales del decir y del silencio. Este "pequeño dios" poeta — para seguir con la metáfora de Huidobro- lo que crea, finalmente, son nuevas relaciones semánticas e imaginativas con las cosas y con los lenguajes de estas mismas cosas; lenguajes que pertenecen, a la vez, a los muchos sujetos, a las huellas de estos en realidad, que habitan (en) la subjetividad del poeta a la hora de materializar la práctica de la escritura. Reveladores de e invitantes a nuevas maneras de sentir la dimensión lingüística de las cosas (y en consecuencia, sentir las cosas mismas), los sintagmas proferidos por este "pequeño dios" - y poco importa si es huidobriano o no- se reportan de facto como divergentes, si es que no subversivos, en relación con aquellas maneras de desplegar el lenguaje en que este -el lenguaje- se invisibiliza en beneficio de una (supuesta) comunicabilidad literal, despojada de ruidos y ambigüedades, supuesta "expresión sincera", directa, de sentimientos y experiencias. La idea de un lenguaje extraterritorializado colisiona de frente con la idea de que el lenguaje primordialmente sería un instrumento que está ahí ya hecho, ya terminado, y que sirve simplemente para hablar en "sentido recto" de las cosas como si tales cosas fuesen, nada más, objetos inertes y completamente ajenos al lenguaje, extra verbales y extra humanas en un sentido absoluto.

"Las cosas son espirituales, no hay separación materia espíritu en el mundo. La materia es inocente; hay que borrarle la sombra del pecado a las cosas, sobre todo al cuerpo" (Millán 2012: 62). Me parece relevante este aserto en la medida en que apuntala la idea de que el creador de poesía sería básicamente aquel tipo de sujeto que se hace cargo, a través de la escritura de textos considerados poéticos, de esta no separación esencial entre materia y espíritu de la que habla Millán. Los mitos y sus reverberaciones narrativas, así como imágenes y símbolos seminales de larga data en la memoria colectiva constituyen, en muchas ocasiones, los subtextos que dotan de sentido metafórico y simbólico a poemas concretos. La creación poética se manifiesta, entonces, como un trabajo de apropiación, adaptación y/o resignificación de narrativas preexistentes que operan, sin embargo, como la estructura simbólica profunda de un poema concreto. Las singularidades literarias tienen, obviamente, sus propias y múltiples genealogías, lo que, por otra parte, pone de manifiesto el intrincado, y nunca garantizado de antemano, trabajo de "traducción" de las experiencias extra verbales implicadas en la escritura poética. Intrincada y laboriosa "traducción" pues, por encima de la complejidad o sencillez formal del texto o artefacto verbal resultante, el poeta construye un punto de cruce de discursos cuyas huellas y voces se convocan en un texto singular y se organizan y jerarquizan según la naturaleza del poema. En este punto, ciertamente, la capacidad de parte del poeta para desplegar un discurso personal de valor identificatorio colectivo, su talento con el lenguaje, su cúmulo de lecturas, sus objetivos comunicativos y expresivos, son factores que cuentan, y son, sin duda, determinantes a la hora de otorgarle al poema una especie de personalidad intransferible. 


\section{INDOCILIDAD REFLEXIVA, INDOCILIDAD IMAGINATIVA}

Puede que Steiner exagere al concebir al creador como una luminosa estrella distante, a varios años luz en relación con el punto en que se sitúa el intérprete, el comentarista, el crítico. Pero si la crítica la vemos como "el movimiento por medio del cual el sujeto atribuye el derecho de interrogar a la verdad sobre sus efectos del poder (sic) y al poder sobre sus discursos de verdad" (Foucault 2018: 62), entonces la crítica no se diferenciaría tanto de la creación poética. "La crítica será el arte — continúa Foucault— de la inservidumbre voluntaria, el de la indocilidad reflexiva. La crítica tendría esencialmente por función la desujeción en el juego de lo que podríamos llamar, en una palabra, política de la verdad" (2018: 62). La "indocilidad reflexiva” de la crítica correspondería, me parece, a lo que yo llamaría "indocilidad imaginativa” en la creación poética, la que admite ser vista, entonces, como aquel "arte de la inservidumbre" que materializa a nivel de lenguaje actuante evocaciones varias de diversos dominios de realidad e inesperadas asociaciones que descentran el domesticado logos de los discursos de los lugares comunes.

Concebir, así no sea de manera solo provisional o con fines metodológicos, la creación poética como crítica implica, por un lado, asumir que la crítica, si es indocilidad discursiva, ha de ser una práctica de extrañeza representacional que hace ver las fisuras, contradicciones, inconsistencias, fallas de un modo de ver/entender el mundo que, hasta antes de la práctica crítica, aparecerían invisibilizadas bajo la tersa superficie de una escena, discursiva o no, presuntamente verdadera, necesaria, sin fisuras. Por otro, implica asumir que la creación poética está lejos de ser un asunto de mera fantasía imaginativa "traducida" a lenguaje metafórico; ha de verse como una práctica de cifrado de mundos posibles que arrancan de la observación y percepciones de las materialidades del mundo real y que se sustentan en la confluencia de discursos en un tipo de textos (normalmente poemas) que, como ya he adelantado, son también, por regla general, "relatos" de la emergencia y conformación de un determinado sujeto lírico.

Este último punto, precisamente, es crucial para lo que aquí nos ocupa: el tipo de sujeto lírico que emerge y se conforma en y con el texto lírico es, en rigor, la imagen de una subjetividad alterna que, al ser confrontada con la subjetividad del propio lector u oyente de la poesía, se produce (o se puede producir) un reacomodo de las percepciones y de la sensibilidad de este al menos en lo que concierne al sector de realidad referido por el poema. Reacomodo que, me parece, toma la forma de una dialógica, pero también de un trabajo y de una tensión, que impacta en los modos de decir y sentir el mundo de parte del lector u oyente. Es decir, el sujeto lírico entra en la subjetividad de los lectores y reclama un lugar propio ahí en ese mundo interior de la vida que entonces queda modificado por la sola presencia de esta voz-personaje, imagen de esa cierta otredad humana que la poesía no cesa de concitar. En ocasiones, este sujeto lírico se queda a vivir en la casa del yo de la vida real por tanto tiempo que termina identificándose, haciéndose uno, con esa casa que en un principio lo acogió. El poema, entonces, se vuelve materia estructurante de esa subjetividad viviente, la que se conforma según las palabras y las reverberaciones de realidad consustanciales al sujeto lírico en cuestión. 
Se podría argüir que el efecto identificatorio de la poesía no es o no tiene por qué ser comprendido como expresión de una cierta crítica. Menos si en determinados contextos tal efecto derivaría del refrendamiento de tópicos ideológicos o de lugares discursivos propios de un orden de cosas que no es cuestionado en absoluto en el poema. Como sería el caso de cierta poesía patriótica en relación con una visión nacionalista preexistente al acto de escribir, visión que informaría y sustentaría a la poesía, a esta poesía en particular, en su devenir lírico. Pero esto sería, en mi opinión, confundir crítica con divergencia de tesis o de opiniones o con confrontación ideológica. Claro está que no puede haber ni actitud crítica ni crítica de facto en el solo acto lingüístico de ratificar un cierto régimen de verdad preexistente a dicho acto. El concepto de crítica que estoy tratando de perfilar, asociado a la creación poética, dice relación con el lenguaje, no con las ideas en un sentido reductoramente argumentativo. Vale decir, con un modo de hablar que pone el acento en sus propios mecanismos de productividad semántica y sus respectivos alcances emocionales y morales, modo de hablar que, como ya se dijo, no se reduce en absoluto a la transmisión de mensajes prefijados. Desde este punto de vista, la indocilidad imaginativa se manifiesta en la forma de un modo alterno de cifrar la experiencia acerca del mundo y con el mundo, cifrado que tiene la particularidad de que, al ser decodificado en el proceso de recepción, abre la puerta para una nueva codificación que no se sujeta simplemente a una visión estrechamente unidimensional del mundo.

Esta "crítica" que acontece a nivel de lenguaje viene a ser, en definitiva, la desafiante práctica de arrancarle a nuestros mundos externos e internos energías semánticas que se desenvuelven sobre estos mismos mundos en la forma de una cierta metamorfosis - no importa lo pequeña que sea- de nuestra relación con ellos de manera que el poema transforma sutilmente nuestro ser. Lo significativo es que, al cambiar la relación, cambian también las realidades involucradas en dicha relación. El lenguaje, como sabemos, hace que las cosas existan en cuanto tales, es decir, con valor y sentido humano. Y si es un lenguaje desterritorializado, como lo es el de la poesía, el mundo, los sujetos, las interrelaciones pluridimensionales que entre ellos acontecen, ganan una nueva oportunidad para escapar, si no de la cárcel del lenguaje, por lo menos de la cárcel de determinados usos y prácticas lingüísticas que, si no se las remece, se vuelven alambradas para el pensamiento, para la imaginación, para la sensibilidad.

\section{PoEsía EN UN MUNDO SIN PROFUNDIDAD}

"Lo que amenaza con desbaratar la sensibilidad verbal es el mundo sin profundidad —afirma Terry Eagleton-, mercantilizado e instantáneamente legible del capitalismo avanzado, con su desampresiva forma de tratar los signos, la comunicación computarizada y su rutilante empaquetamiento de la 'experiencia" (2010: 26). Tal como el mismo Eagleton sostiene, lo que está verdaderamente en peligro en nuestro mundo actual es la experiencia misma (itálicas del autor, Cf. 2010: 26), que, de haber sido en alguna época el modo en 
que los acontecimientos vividos y sus repercusiones se volvían patrimonio "duro" de la memoria, se ha vuelto, al decir del mismo Eagleton, algo tan "precocinado como una pizza" (2010: 27): "Es como si hubiese una experiencia flotando en el aire, esperando que un ser humano se acerque y la tome" (2010: 27). Discutir sobre el desgaste de la experiencia en los tiempos del capitalismo tardío nos llevaría por derroteros ajenos al tema de estas reflexiones, de manera que el asunto lo dejo enunciado como reto al ejercicio de comprender qué clase de tiempos son los que estamos viviendo. La devaluación de los signos, sin embargo, es un asunto que a la poesía no le es en absoluto indiferente.

$\mathrm{Si}$ ese mundo "sin profundidad", en el que los grandes mitos y sus rigurosos rituales verbales no tienen ya lugar —no en la centralidad de la vida social por lo menos-, resulta ser una fábrica de experiencias despojadas de acontecimiento, por lo tanto, fábrica de subjetividades "flotantes" tan precocinadas como las pizzas, la poesía, a contracorriente de ese mundo, se manifiesta como una práctica lingüística que trabaja con el lenguaje de manera que los signos se vuelvan acontecimiento. Y lo hace, casi siempre, en y desde la periferia de la semiósfera del capitalismo tardío, a contrapelo de la devaluación del lenguaje, aunque no necesariamente como un efecto planificado sino simplemente por el hecho mismo de que la poesía no puede sino crear extrańeza por su solo decir. El poema, aun en su condición de "no-poema" (como los ejercicios de escritura azarosa que propugnaban los dadaístas o la actual escritura poética hecha por máquinas a partir de algoritmos), nunca deja de ser un llamado de atención sobre el lenguaje, sobre sus modos de producir sentido y su evanescente referencialidad que nos obliga a revisitar con extrańeza nuestra acostumbrada y convencional relación (lingüística y no lingüística) con la realidad del mundo. Incluso si la cuestión de la ausencia de profundidad fuese - $\mathrm{y}$ en muchos casos lo es- la marca distintiva de determinadas prácticas poéticas más o menos postmodernas, tal ausencia es paradójicamente su profundidad, por lo que no deja de ser un desafío a aquellas prácticas lingüísticas en la que la ausencia de profundidad es literal.

La poesía es una manera de fenomenología del lenguaje, una en la que la relación entre palabras y significados (o significado y significante) es más estricta que en el lenguaje ordinario. Hay muchas formas de decir "Tome asiento", pero solo una manera de decir "La liebre saltaba estremecida entre la hierba helada". La poesía es el lenguaje en el que el significado o sentido es el proceso global de la propia significación. Es, por lo tanto, un lenguaje que siempre, en algún nivel, trata de sí mismo (Eagleton 2010: 31).

Esta relación más estricta entre palabras y significado, relación singular no intercambiable, convierte al poema en un acontecimiento que exige una especial atención a su lenguaje tanto como a aquel sector de realidad referido por ese lenguaje $y$, sobre todo, a lo que el poema produce en la subjetividad del lector/oyente: un conglomerado de pensamientos, emociones, asociaciones conceptuales e imaginativas, evocaciones diversas, etc. "Poesía — añade Eagleton - es algo que se nos hace a nosotros, no solamente que se 
nos dice. El significado de sus palabras está fuertemente vinculado a la experiencia de ellas" (2010: 31). Experiencia que, por su naturaleza multidimensional y dinámica, no puede ser simplemente "precocinada", empaquetada, intercambiable. Al revés: la experiencia que suscita el poema la podemos concebir como un pequeño big bang cuyas energías semánticas salen disparadas en múltiples dimensiones y direcciones llegando a configurar, en sus tratos con la memoria e imaginación del lector, imágenes y conceptos que, eventualmente, pueden tener un peso específico de alto impacto en la conformación, modificación y/o administración de la subjetividad de este.

Por esta vía, la poesía viene a manifestarse como el lugar, dentro de la escena de la vida humana, en que halla exactitud lingüística lo inexacto del mundo; una forma de decir que las maneras caóticas, no lineales, polisignificativas, que desbordan esquemas convencionales de comprensión, con las que la realidad de la vida se hace, a menudo, presente en nuestra conciencia reclamando reconocimiento y lugar en el discurso humano, hallan sitio en la poesía justamente; como si la poesía fuera (o permitiera) la emergencia de aquella zona del ser en la que las formas del mundo huyen despavoridas de las consabidas jaulas del lenguaje, esas que, por desgastadas, poco o nada pueden decir de lo nuevo emergente, o que, por exigencias institucionalizadas de una literalidad unívoca, se perciben como un campo de restricciones semánticas contrarias a la poiesis del lenguaje y de las cosas.

Que el lenguaje de la poesía "siempre, en algún nivel, trate de sí mismo" es, sin duda, una forma de indocilidad ante aquellas formas de lenguaje que crean y sustentan la ilusión de que el lenguaje es solo un medio a través del cual, en la forma de mensajes comunicativos, viaja la realidad extra verbal (codificada) de una conciencia a otra. La poesía nos enseńa que no existe ninguna realidad extra verbal, si por ello entendemos un mundo material allá afuera desconectado, en sentido absoluto, del lenguaje. El mundo material es tributario del lenguaje que lo nombra tanto como el lenguaje lo es del mundo material en la medida en que el lenguaje está obligado a referirse a realidades que entonces, por ser referidas precisamente, cobran sentido humano. La poesía es un tipo de discurso en que el asunto de la recursividad entre palabra y mundo no verbal se vuelve materia de primerísimo orden, tanto que, y sin exagerar demasiado, cada poema lo podríamos ver como una aproximación imaginativa a una o a algunas de las muchas, quizás infinitas, maneras en que el lenguaje oculta tanto como devela los intríngulis más íntimos, más dramáticos también, de la realidad de la vida aconteciendo en situaciones concretas. Tan concretas y singulares que su traducción a palabras se vuelve igualmente singular, única, no intercambiable por otra.

Visto así, la poesía es una conciencia vigilante ante el constante peligro de que el lenguaje se vuelva retórica alienada, expresión de ideologías o visiones que renuncian a ver el tránsito recursivo entre las palabras y las cosas y a la mutua y necesaria vigilancia entre estos órdenes de realidad en beneficio de ciertos discursos hipertrofiados hasta el paroxismo. La poesía, aun la más militante, si sigue siendo poesía (y no simple alabanza, por ejemplo), siempre será una oportunidad para que la realidad, aquella que hace tratos con la poesía, se manifieste en su plenitud multidimensional. Y el registro verbal de esta realidad multidimensional será igualmente la oportunidad para que el lenguaje se vuelva 
sobre sí mismo, en un gesto metalingüístico que es el recurso que tiene el lenguaje para representar lo impresentable del mundo; impresentable en el sentido de aquello que nunca puede manifestarse a la inmediatez de la percepción o la experiencia sin una compleja mediación lingüística. Si tiene algún sentido hablar de la poesía como crítica, diríamos que la poesía es menos una crítica con el lenguaje — como lo sería la crítica razonada y argumentativa - y mucho más una crítica en el lenguaje: una indocilidad que sucede en el acto mismo de producir enunciados que llegan a conformar un artefacto poético como respuesta-propuesta a la pretensión de cifrar ("traducir", diría Gonzalo Millán) y relatar una determinada relación humana con el mundo escenificada en un texto que empieza por tensionar, si es que no abiertamente cuestionar, el propio lenguaje que conforma dicha la relación, dando paso a una conciencia de la conciencia pensante y sintiente que sostiene al lenguaje y que se sostiene en él. Una subjetividad especular, distanciada de sí misma, que en la poesía adquiere la forma de sujeto lírico.

El poeta, cuando escribe, se vale, como cualquier artista, de eso que se llama la experiencia, término que quisiera utilizar aquí de la manera más amplia: como todo aquello que, en forma de acción, sentimiento o pensamiento ha pasado por su conciencia. Esa experiencia, que es traída al momento de la escritura por medio de la memoria, es, antes de ser fijada por la palabra, algo móvil, hasta cierto punto inasible. Consignarla es, en buena medida, congelarla, pero de tal modo que no pierda en absoluto su poder de complejidad y vivacidad. [...] Pero como la poesía no es, no puede ser, un ejercicio confesional de vivencias íntimas, aunque algo de eso pueda haber en ella, debe darse también un proceso de distanciamiento, que se logra, en primer lugar, a través de la búsqueda de la palabra justa. Ese solo proceso, a mi modo de ver, es ya liberador, en la medida en que una buena parte de la energía creativa se encauza por la vía de lo formal que exige una racionalidad crítica y se aparta de las conmociones que causa acercarse de nuevo a la experiencia (Bonett 2009: 94).

"Palabra justa", es decir, palabra precisa, pero, sobre todo, palabra que haga justicia, en el recto sentido del término, a aquellas realidades que reclaman ser dichas dando cumplimiento a una exigencia moral —no solo estética — ineludible. "Palabra justa" que implica discernimiento, arduo trabajo de búsqueda y de ensayos lingüísticos (estilo, tono, constelación simbólica, etc.), eso sin contar los desvelos (literales) que anteceden, a veces por largo tiempo, a la aparición del poema. Acaso uno de los mayores riesgos que debe sortear la poesía sea el de no convertirse en un discurso crítico sensu estricto, algo que puede sonar paradójico cuando más arriba he sostenido que la creación poética sí es una forma de crítica. La "razón-poética", por usar un término con el que Chantal Maillard expone y discute lo que ella formula como "la creación por la metáfora" (Cf. 1993: 114 y ss.), se articula en un terreno lingüístico de gozo y padecimiento en directa correlación con el libre y placentero trabajo de la imaginación controlado, sin embargo (si es que no abiertamente 
trabado) por el peso, a veces opresivo, de una realidad que se resiste a ser simbolizada (no olvidemos que toda realidad, en diversos grados, ofrece esta resistencia).

Si la razón poética (esta vez escrito el término sin guion, como originalmente lo propuso María Zambrano $)^{7}$ despliega crítica, lo hace, tal como se ha sugerido en párrafos anteriores, a través de la movilización de un lenguaje que se resiste igualmente a ser simbolizado de otro modo que no sea el de su singularidad dada en el poema. En este punto la poesía, o el poema para ser más preciso, se vuelve una suerte de réplica analógica de su propio referente, el que, por otra parte, está lleno de resonancias de sentido que se expanden en diversas direcciones y desde diversas dimensiones, porque tal referente es construido en el lenguaje poético.

La razón-poética es apertura para la visión, camino hacia la visibilidad, estado de atención y disponibilidad para el conocimiento de un ser que en esa tensión hacia la apertura se realiza. La razón-poética es, por tanto, acción ética y estética por cuanto que es acción creadora esencial a la vez que existencial, acción que solamente puede realizarse plenamente cuando aquello en lo que estamos (objeto de nuestra acción, cualquiera sea) ocupa toda nuestra atención, es decir, cuando en ello va nuestro ser. El hombre nace en la medida en que se entrega, en la medida en que muere a sí mismo (sic) [...] Solamente así se cumple la acción creadora, pues solamente así el impulso creador obtiene la fuerza suficiente para ser eso: pura fuerza creadora, libre de determinaciones, libre para cumplirse en sí misma, libre para ser lo que llamamos azar: fuerza vibrátil, transformadora, mágica (Maillard 1993: 125).

La "poesía como crítica", entonces, hay que verla — lo reitero— más en lo que la poesía hace en el lenguaje y en lo que ese lenguaje, el de la poesía, hace en nuestra conciencia. Y menos en lo que la poesía hace con el lenguaje. El resultado de este hacer puede que sea incierto, ajeno o refractario a toda medición o categorización abstracta, pero será siempre la ocasión en la que la vida, en el mejor sentido del término, ingrese al decurso de los significados lingüísticos; e ingrese no como un mero referente "exterior" sino como una energía creadora que inaugura entidades y relaciones nuevas que siempre en algo modifican nuestra morada vital a la vez que le dan a esta continuidad y sustentabilidad simbólica. La "indocilidad" de la que habla Foucault halla su lugar predilecto en la poiesis; en esa energía que no se ajusta nunca del todo a ningún esquema imaginativo o conceptual, pero que, al mismo tiempo, no adquiere valor humano si no es en la medida en que puede ser imaginativa y conceptualmente modelada de alguna manera que halle sentido en el seno de la vida social. Un modelamiento siempre provisional, eso sí; siempre "incompleto" pero al mismo tiempo invitante a nuevas posibilidades de mundo y de lenguaje. En un sentido, entonces, la poesía es un esfuerzo por materializar en el lenguaje la recuperación de las cosas mismas dando cabida a una especie de fenomenología radical signada por la singularidad.

${ }^{7}$ Cf. Filosofía y poesía y Claros del bosque de María Zambrano, publicados en 1939 y 1977 respectivamente. 
Por otro, es la verbalización de la imposibilidad de que semejante empresa se realice, o sea, se haga realidad en sentido literal. Se realizará entonces en sentido figurado, evidenciando así el poder instituyente de la metáfora a la hora de transmutar las intolerables insolencias de la realidad en el fluir de la palabra mayor que recorre, refrescando y hasta purificando a veces, la totalidad de nuestro ser.

\section{A MODO DE CONCLUSIÓN: SOBRE LA SUSTENTABILIDAD SIMBÓLICA}

"Váyanse, váyanse, váyanse, dijo el pájaro: la especie humana / No puede soportar demasiada realidad" (trad. mía). ${ }^{8}$ Así escribió Eliot haciendo alusión a que los seres humanos no toleramos la realidad sin una necesaria dosis de ficción, acaso también de mentira, para hacerla soportable; lo cual habla de la dimensión monstruosa con la que la realidad puede llegar a manifestarse. No podemos sino construir nuestros mundos en nosotros a partir primariamente del diálogo humano y de lo que nuestro sistema perceptivo registra acerca de las materias de ese mundo que está ahí afuera y que, de un modo u otro, es el lugar que habitamos y nos habita. Lo que registramos también lo guardamos. El rol de la memoria, consciente o no, es fundamental; sin este complejo sistema orgánico-mental de selección, almacenamiento y organización funcional de la información simplemente no podríamos existir en tanto humanos. A lo que hay que ańadir la imaginación: esa capacidad para construir en nuestra mente mundos alternos a partir de la información que nos constituye, mundos alternos de naturaleza mental que pueden o no derivar en la aparición de nuevas realidades materiales y en los cuales nosotros mismos llegamos a ser recursivamente otros en nosotros.

Se le atribuye a Epicteto la máxima de que "los hombres no sufren por los hechos, sino por la representación de los hechos";" otra manera de decir que la "insoportable" realidad puede a veces tomar la forma de un discurso doloroso, de sufrimiento en este caso, y que puede llegar a estructurar al menos una zona de nuestra subjetividad. Lo cierto es que hecho y representación de ese hecho no son separables sino solo en aquel escenario en que esta separación, por motivos analíticos u otros, resulta indispensable hacerla, lo que

\footnotetext{
8 "Go, go, go, said the bird: human kind / Cannot bear very much reality", leemos en el original. Los versos pertenecen al poema "Burt Norton", Cuarteto Nro. 1, de libro Cuatro cuartetos de T. S. Eliot. Cito en inglés de una versión en línea disponible en http://www.davidgorman.com/4quartets/.

${ }^{9}$ La frase se ha traducido o interpretado en realidad de varias maneras: "No son las cosas que nos pasan las que nos hacen sufrir, sino lo que nosotros nos decimos sobre esas cosas". O también "Tu felicidad depende de tres cosas, todas las cuales están en tu poder: tu voluntad, tus ideas sobre los eventos en los que te involucras y el uso que haces de tus ideas". Las máximas de Epicteto se han vuelto muy populares en programas y textos de auto ayuda. Recordemos que Epictecto no dejó textos escritos; lo que se conoce de su pensamiento es gracias a los escritos de Lucio Favio Arriano, discípulo de Epictecto. Para un comentario estrictamente filosófico y filológico de la filosofía de Epicteto remito al lector interesado al artículo "Sobre el 'arte de vivir' en Epicteto" de Germán A. Meléndez.
} 
requiere, claro está, elaborar un cierto discurso sobre el hecho y la representación del mismo. En el devenir de las experiencias elementales, primarias, los hechos son al mismo tiempo las representaciones que nos construimos de ellos. Es más, si un hecho no lo representáramos en tanto tal, como hecho justamente, este no existiría en absoluto para nosotros. En este nivel perceptivo elemental puede que la conciencia discursiva (o metadiscursiva) sea muy débil o incluso inexistente, caso en el cual la verdad parecerá que corre por su cuenta al margen de la representación que hemos construido de las cosas y de la verdad misma. Estaríamos más bien, sin saberlo, ante una ilusión de verdad "desnuda" simplemente porque no vemos las ropas con que la cubrimos. Me atrevo a sostener que la literatura, en particular la poesía, al ser una de las formas de nuestra dialógica vital en que la práctica de producir sentido se hace atendiendo a los recursos del lenguaje, a sus efectos imaginativos, a los modos en que el lenguaje se manifiesta y funciona en textos concretos, se vuelve crucial para fijar atención y cuidado en el trabajo de los signos hacedores de mundos. Es decir, la poesía trabaja a contracorriente de la degradación de los signos y otorga, por eso mismo, profundidad a las cosas.

Decía más arriba que toda realidad, en diversos grados, se resiste a ser simbolizada. Sí, en la medida en que producir textos siempre es un trabajo, una práctica, un esfuerzo por aprehender algo y decirlo, y producir con lo dicho determinados efectos. Y aunque ese algo no es ni será nunca idéntico a lo que de ese algo decimos — conciencia de la diferencia que se hace singularmente nítida al escribir poesía-, nuestra tarea, en tanto hablantes de una lengua, es hacer que signo y referente sean "idénticos" en el flujo de la actividad comunicativa. Desde este punto de vista, la poesía la podríamos concebir como el ejercicio de hacer que el decir y lo dicho sean de verdad idénticos, porque en la poesía la acción de decir y lo dicho en y por esta misma acción de decir refieren, en última instancia, al propio lenguaje.

Se trata, sin embargo, de un ejercicio paradójico, pues el lenguaje está hecho, entre otras cosas, para referir el mundo extra verbal, cuya condición de tal — de extra verbal - no puede ser simplemente cancelada o ignorada so pena de convertir al lenguaje en un parloteo carente de sentido. Paradójico porque, además, en este contexto, el propio lenguaje, al volverse sobre sí mismo, se vuelve una realidad extra verbal en cuanto referente. Tratar con esta paradoja, que en el ejercicio poético concreto puede volverse desgarradora contradicción, es también tarea de la poesía. Simbolizar lo real con la poesía es fijar con palabras, representar lingüísticamente, el flujo elusivo del mundo en la forma de textos que negocian, de una manera u otra, con un cierto conjunto de convenciones estéticas. Y en la medida en que la poesía trata con la fantasía, con las emociones, con la belleza del decir (no necesariamente con la de la realidad representada), con el propio lenguaje, se torna en un trabajo lingüístico orientado a producir una cierta ecología simbólica disponible para que los sujetos reales, las personas, den paso a formas de sustentación de sí mismos a la hora de tratar con las dificultades de la vida: con los hechos y sus representaciones y con los hechos constituidos por estas mismas representaciones; un hecho representado como hecho es ya un hecho constituido por la representación del hecho representado. 
Un poema es energía almacenada, una turbulencia formal, una cosa viviente, un remolino en la corriente.

Los poemas son parte de los flujos de energía que sustentan la vida.

Los poemas son equivalente verbal del combustible fósil (energía almacenada), solo que son fuentes renovables de energía; energía que proviene, en el caso de los poemas, siempre de estas dos matrices generativas: el lenguaje y la imaginación (Rueckert 1996: 108, trad. mía).

Agregaría yo una tercera matriz generativa: la memoria, aspecto ya tocado en otra parte de esta exposición. No obstante la ausencia anotada, suscribo las tesis de Rueckert a modo de (provisional) conclusión e invitación a ingresar con confianza a la casa de la poesía, meditar sobre su valor, su funcionamiento y sus efectos en el lenguaje. Plantear la creación poética como crítica ha sido más un pretexto que una tesis, a partir del cual he tratado de elaborar una aproximación a la poesía enfocada a relevar el valor emancipatorio, crítico por eso mismo, de sus significaciones en sus tratos con la subjetividad. Emancipatorio en cuanto que la necesaria extrańeza representacional a las que nos impele el lenguaje de la poesía, sea que estemos en el rol de autor o de lector u oyente, nos obliga a atender con cuidado a los vastos efectos del lenguaje, en la forma de discursos ciertamente, en su rol instituyente y constituyente de la subjetividad, así como en el modelamiento de nuestra relación de sentido con la dimensión material del mundo, externa al sujeto. Y también entiéndanse estas reflexiones como un llamado a atender a la máxima de Epicteto, pero en un sentido invertido: "los seres humanos no gozan, no son felices por los hechos, sino por la representación de los hechos". Porque puede que la poesía no nos haga ni felices ni mejores, pero nunca nos hará ni infelices ni peores.

\section{OBRas Citadas}

Appratto, Roberto. 2018. "Mallarmé y una frase capital sobre la literatura". Escaramauza. Libros y café. https://escaramuza.com.uy/nota/mallarme-y-una-frase-capital-sobrela-literatura/362 (web) [12-07-2020].

Auden, W. H. 2013. "Leer”. El arte de leer. Ensayos Literarios. Trad. Juan Antonio Montiel. Barcelona: Lumen. 24-40.

Bonett Vélez, Piedad. 2009. "Apuntes sobre el proceso de la creación poética”. Desde el Jardin de Freud 9: 89-95.

Coble Sarro, David. 2015. "Límite de mi lenguaje como límite de mi mundo". Revista de Filosofía Factótum 13: 45-69.

Eagleton, Terry. 2010. Cómo leer un poema. Trad. Mario Jurado. Madrid: Akal.

Eliot, T. S. 2000. Four Quartets. http://www.davidgorman.com/4quartets/ (web) [12-07-2020].

Etimología de la lengua española. Definiciones sobre el origen del léxico castellano o español. https://etimologia.wordpress.com (web) [7-07-2020]. 
Foucault, Michel. 2018. ¿Qué es la crítica? Seguido de La cultura en sí. Sorbona, 1978 / Berkeley, 1983. Trad. Horacio Pons. Buenos Aires: Siglo XXI (ebook).

Huidobro, Vicente. 2011. El Espejo de Agua y Ecuatorial. Santiago: Pequeño Dios Editores. Maillard, Chantal. 1993. "La creación por la metáfora". Debate Feminista V. 7: 114-125.

Meléndez, Germán A. 2014. “Sobre el 'arte de vivir' en Epicteto”. Eidos 20: 271-310.

Millán, Gonzalo. 2012. La poesía no es personal. Santiago: Alquimia Ediciones.

Real Academia Española. 2019. Diccionario de la Lengua Española. Edición Tricentenario. https://www.rae.es/ (web) [7-07-2020].

Rueckert, William. 1996. "Literature and Ecology. An Experiment in a Ecocricism”. The Ecocriticism Reader. Landmark in Literary Ecology. Eds. Cheryll Glotfelty \& Harold Fromm. Athens: University Georgia Press. 105-123.

Steiner, George. 2016. Un largo sábado. Conversaciones con Laure Adler. Trad. Julio Barquero Cruz. Madrid: Siruela.

Wittgenstein, Ludwig. 1987. Tractatus logico-philosophicus. Trad. Jacobo Muñoz \& Isidoro Reguera. Madrid: Alianza Editorial.

Zambrano, María. 2006. Filosofía y poesía. México: Fondo de Cultura Económica. . 1988. Claros del bosque. Barcelona: Seix Barral. 
